\title{
Survival of Gallbladder Cancer with Infiltrative Node Beyond the Hepatic Pedicle
}

\section{Salah Berkane*}

Head of Visceral and Oncologic Department of Surgery, Teaching Hospital, Smina Bejaia, Faculty of Medicine, University of Bejaia, Algeria

*Corresponding Author: Salah Berkane, Head of Visceral and Oncologic Department of Surgery, Teaching Hospital, Smina Bejaia, Faculty of Medicine, University of Bejaia, Algeria.
Received: January 18, 2020

Published: April 18, 2020

(C) All rights are reserved by Salah Berkane.

\begin{abstract}
Gallbladder cancer is very lymphophilic and this feature remains one of the leading bad prognostic factors. To achieve a radical character in liver resection surgery more or less extended needs to be associated with lymphadenectomy. Lymphadenectomy interesting the hepatic pedicle is the most done technic. Few surgeons perform extended lymphadenectomy realize extended lymphadenectomy to remove a maximal lymph especially the node beyond the hepatic pedicle with a hope to ameliorate the prognosis of disease. We have adopted extended lymphadenectomy and we report long terms results for the patients who presented infiltrative node above the hepatic pedicle in view of survival at 5 year. Patient and method: We report all patients operated on for gallbladder cancer and benefited from extended lymphadenectomy. Two hundred and four patients benefited from extended lymphadenectomy. One hundred had no node infiltration and 104 had node infiltration. Between these 104 patients, 68/104 (65,4\%) had infiltrative node above hepatic pedicle. A total number of nodes was 1172 with mean of 17,5nodes per patient (03-36nodes) and ratio of infiltrative nodes was 31,5\%. For pT1, pT2, pT3 and pT4, the percentage of infiltrative nodes was respectively $00 \%, 03 \% ; 45,6 \%$ and 51,4\%. Nighty-seven percent of infiltrative nodes were for pT3 and pT4. N1, N2 and N3 were distributed are follow: 36 (34,6\%), 39 (37,5\%) and 29 (27,9\%). The morbidity and mortality were 32,5\% and 13,5\%. Three and 5-year survival rate were 20,5\% and 10,3\% for the entire series and $30,6 \%$ and $16,3 \%$ for R0 resection. Conclusion: Patients with infiltrative nodes behind hepatic pedicle do not have a worse prognosis in all cases. Radical surgery with extended lymphadenectomy must be carefully realized when R0 resection can be achieved for patient fit for aggressive surgery.
\end{abstract}

Keywords: Gallbladder Cancer; Extensive Lymphadenectomy; Global Survival; Infiltrative Nodes

\section{Introduction}

Gallbladder cancer is very lymphophilic [1] and this feature remains one of the leading bad prognostic factors [2]. To achieve a radical character in liver resection surgery more or less extended to one or more adjacent organs is necessary but not sufficient. This radical resection requires lymphadenectomy [3] with hepatic resection. Few surgeons make the extended lymphadenectomy retrieve a great number of lymph node and especially those localized beyond hepatic pedicle. The goal of its practice is an improvement of the prognosis. Some authors perform a lymphadenectomy of the common hepatic artery and reverse duodenopancreatic [4]. Only the Japanese authors go to achieve a lymphadenectomy of the inter-aorto-cellar area. In the West, the presence of lymph node infiltrated in inter-aorto-cave area are considered as distant metastases and contre-indicate radical resection [5-7]. The patients with infiltrated lymph node in inter-aorto-caval have a poor prognosis by contribution to those who are free. It is the same for those with infiltration of the lymph nodes at the common hepatic channel and the celiac trunk [8]. Since the 1997 and 1988 classifications of the UICC and AJCC and various subsequent updates, reaching beyond the pedicle are considered as distant metastasis and resection is contraindication of radical surgery [9-10]. We have adopted over twenty years conducting extensive lymphadenectomy during radical surgery of gallbladder cancer on a routine basis. In this series of extensive lymphadenectomy, the reality of lymph node involvement beyond the hepatic pedicle proved common. The aim of this study is to know if an extended lymphadenectomy can achieve 5 -year survival for patients with infiltrative lymph nodes beyond hepatic pedicle. 
Patients and method

The radical surgery for gallbladder cancer in our daily practice fellow these ways: hepatectomy type IV-V bisegmentectomy for all tumors classified pT2, pT3 and pT4. The extent of this hepatectomy is suitable for locoregional invasion met the patient. In a first period, the tumors classified pT1a PT1b and were treated by a simple cholecystectomy without lymphadenectomy. Since 5years, the pT1b tumors are treated by IV-V bisegmentectomy. The extensive lymphadenectomy is performed from the hilum until inter-aortocaval area in combination with hepatectomy or the reverse. It is performed as follows: removal of all nodes of the hepatic pedicle, followed by that of the common hepatic artery and the right side of the celiac trunk, followed by the posterior surface of duodenopancreatic block and inter-area aortico- cellar. In some cases, removal of lymph nodes in the superior mesenteric artery, those of gastroepiploic right group, the mesocolon, and splenic artery is performed according to the extension of the resection gesture dictated by the tumor extension. Radical surgery is successful in patients classified ASA I, II, III (without associated visceral disease with tare controlled or in some cases with associated disease well controlled before surgery) without diffuse liver and peritoneal metastases, absence of pulmonary metastases.

Lymph and lymph node relay gallbladder cancer are defined in the following way:

- N1: Lymph nodes and the liver pedicle (neck ganglion or Mascagni node, biliary duct node, portal vein node, lymph nodes in the proper hepatic artery (Figure 1)

- N2: lymph and retro-duodeno-pancreatic lymph nodes and those of the common hepatic artery. (Figure 2)

- N3: lymph nodes and the celiac trunk (right flank) and those of the inter-aorto-cellar area.

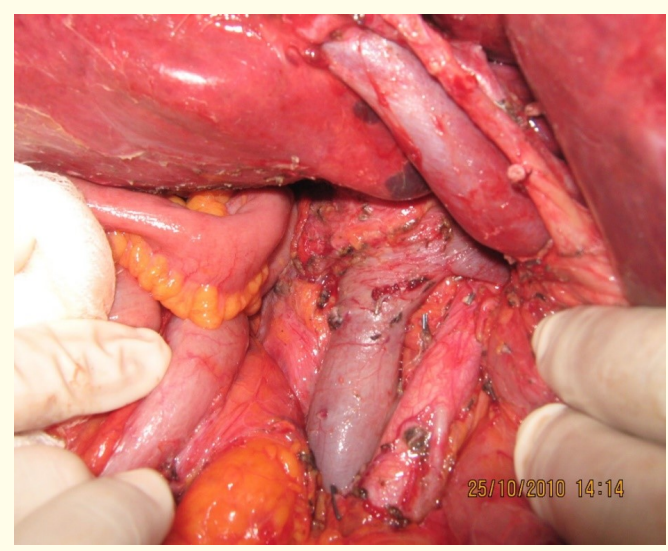

Figure 1: Hepatic pedicle and aorto-caval area dissected with lymph node resected. Close view.

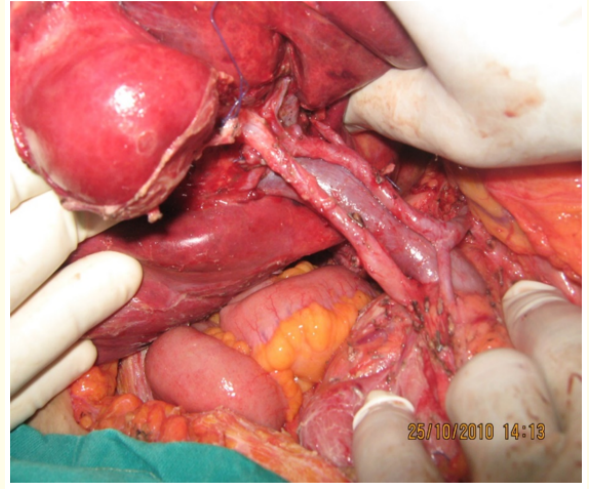

Figure 2: Hepatic pedicle dissected with nodes removed, Distant view.

For some patients resected lymph nodes may be well beyond these areas (nodes of the superior mesenteric artery, those of gastroepiploic right group, the mesocolon, and the spleen artery). All patients underwent surgery and who received extensive lymphadenectomy and whose histological study showed an infiltration beyond the hepatic pedicle were included in the analysis. In our practice, pancreatoduodenectomy resection is the deduction for a patent visceral invasion or ineradicable nodes, which need this resection for total node ablation. Each group of nodes is fixed in formalin in a bottle apart after dissection outside of the surgical field by the surgeon. Each bottle is labeled and set apart as the main operating room. The samples are sent for histological analysis. Histological study was performed by the technique of hematoxylin-eosin and immunohistochemistry study technique was not be not used in this study. The parameters studied were:

- $\quad$ Preoperative and histological parameters: age, sex, associated disease, macroscopic tumor histological type, pTNM, TNM stage, the number of lymph nodes resected relay and patients, the total number of resected lymph nodes, the ratio of infiltrated nodes, presence of perineural infiltration, the presence of vascular emboli.

- Postoperative complications: vascular wounds, bile duct injuries, ...., and postoperative mortality and its cause.

- Long terms parameters: prescription of adjuvant chemotherapy, recurrence and places, treatment of recurrence and survival at 3 years and 5 years.

\section{Results}

Two hundred thirty-nine patients 204 have benefited from extended lymphadenectomy. There were 180 femeles and 24 males with mean of age of 58years (26 - 83years). A total of 1172nodes were resected with a mean per patient of 17,5 nodes (03-54nodes). 
The mean nodes per patient level was 06 (01 - 20nodes) and ratio of infiltrative nodes was $31,6 \%$. One hundred patients were N0, 36 N1, 39 N2 and 29 N3. $68(65,4 \%)$ had infiltrative node beyond the hepatic pedicle. Regarding for pT1, pT2, pT3 and pT4, percentage of infiltrative node were respectively $00 \%, 03 \%, 45,6 \%$ and $51,4 \%$ (Table 1). The most infiltrative relay were neck node, bile duct nodes, portal vein nodes, common hepatic artery node and retroduodenopancreatic nodes (Table 2). The morbidity and mortality were respectively $32,5 \%$ and $13,5 \%$. Global 3 and 5year survival for the entire series are $30,6 \%$ and $16,3 \%$ for the R0 resection and out of postoperative mortality (Table 3 ).

\begin{tabular}{|l|l|}
\hline Sex: & \\
Females & 180 \\
Males & 24 \\
Age & $58 y e a r s(26-83 y e a r s)$ \\
\hline All nodes resected & 1172 \\
\hline Mean of node per patient & $17,5(03-54)$ \\
\hline Mean of nodes per level & $06(01-20)$ \\
\hline Ratio of infiltrative nodes & $31,6 \%$ \\
\hline Level of lymph infiltrated & \\
\hline N0 & $49 \%(100 / 204)$ \\
\hline N1 & $34,6 \%(36 / 104)$ \\
\hline N2 & $37,5 \%(39 / 104)$ \\
\hline N3 & $27,9 \%(29 / 104)$ \\
\hline N2 + N3 & $65,4 \%(68 / 104)$ \\
\hline Infiltrated node according to T & \\
\hline T1 : 00 & 00 \\
\hline T2 : 2/68 (3\%) & $03 \%(\mathrm{~N} 2: 1$ and N3 : 1) \\
\hline T3 : 31/68 (45,6\%) & $45,6 \%(\mathrm{~N} 2: 19$-N3 : 12) \\
\hline T4 : 35/68 (51,4\%) & $51,4 \%(\mathrm{~N} 2: 19-\mathrm{N} 3: 16)$ \\
\hline
\end{tabular}

Table 1: Patients characteristics.

\begin{tabular}{|l|c|c|c|c|}
\hline Morbidity & \multicolumn{2}{|c|}{66} & \multicolumn{2}{c|}{$32,5 \%$} \\
\hline Mortality & \multicolumn{2}{|c|}{28} & \multicolumn{2}{c|}{$13,5 \%$} \\
\hline Survival & \multicolumn{2}{|c|}{$\mathrm{N} 2$} & $\mathrm{~N} 3$ & $\mathrm{~N} 2+\mathrm{N} 3$ \\
\hline $\begin{array}{l}\text { Global (R0-R1- } \\
\text { R2+postoperative } \\
\text { mortality) }\end{array}$ & 3years & $\begin{array}{c}10 / 39 \\
(25,6 \%)\end{array}$ & $\begin{array}{c}4 / 29 \\
(13,8 \%)\end{array}$ & $\begin{array}{c}14 / 68 \\
(20,5 \%)\end{array}$ \\
\hline & 5years & $\begin{array}{c}4 / 39 \\
(11,5 \%)\end{array}$ & $\begin{array}{c}3 / 29 \\
(10,3 \%)\end{array}$ & $\begin{array}{c}7 / 68 \\
(10,3 \%)\end{array}$ \\
\hline $\begin{array}{l}\text { R1+R2*+ Mortality } \\
\text { excluded }\end{array}$ & 3years & $\begin{array}{c}11 / 31 \\
(35,5 \%)\end{array}$ & $\begin{array}{c}5 / 18 \\
(27,8 \%)\end{array}$ & $\begin{array}{c}15 / 49 \\
(30,6 \%)\end{array}$ \\
\hline $\begin{array}{l}\text { R0 and out of post- } \\
\text { operative mortality }\end{array}$ & 5years & $\begin{array}{c}5 / 31 \\
(16,1 \%)\end{array}$ & $\begin{array}{c}4 / 18 \\
(16,7 \%)\end{array}$ & $\begin{array}{c}8 / 49 \\
(16,3 \%)\end{array}$ \\
\hline
\end{tabular}

Table 2: Relay of infiltrative nodes.

\begin{tabular}{|l|c|c|}
\hline Relay of nodes & $\begin{array}{c}\text { Number of infiltrative } \\
\text { nodes }\end{array}$ & $\mathbf{\%}$ \\
\hline Neck node (Mascagni) & $16 / 17$ & 94,1 \\
\hline Bile duct node & $24 / 34$ & $70,5 \%$ \\
\hline Proper hepatic artery & $14 / 37$ & $37,8 \%$ \\
\hline Portal vein & $34 / 43$ & $79 \%$ \\
\hline Rétro-duodéno-pancreatic & $41 / 47$ & $87,2 \%$ \\
\hline Common hepatic artery & $31 / 53$ & $58,5 \%$ \\
\hline Inter-aortico-cave & $23 / 58$ & $38,6 \%$ \\
\hline Coeliac trunk & $6 / 26$ & $23 \%$ \\
\hline
\end{tabular}

Table 3: Morbidity, mortality and 3 and 5year survival.

*: There is no survival beyond 18months for R1-R2 (mean survival 10,5 mois (4-18mois)

R0: none residual tumor

R1: microscopic residual tumor

R2: macroscopic residual tumor.

\section{Discussion}

The lymph node is an important reality in the surgery of gallbladder cancer. Ogura., et al. [1] published the results of a multicenter study in 1991 involving 1686 cases of resection. The lymphatic and lymph node involvement were respectively $3.5 \%$ to $84.8 \%$ and from $2.5 \%$ to $74.4 \%$ starting from the purely mucous tumor that touching and exceeding the serous. This means that this attack is real, constant and frequent. In this series, the overall achievement of $51 \%$ and lymph node involvement beyond the hepatic pedicle is $65 \%$. The counts reported in the literature are greater than $50 \%$ and can reach the same rate of $73 \%$ [8]. For lymph node infiltration beyond the hepatic pedicle, Yamaguchi [11] reported a rate of $28.5 \%$ in N1, N2 to $17 \%$ and $18.6 \%$ in N3. For Kondo [8], lymph node involvement was 73\% in N1 and N2 and N3 38\%. Some authors have reported pure nodal recurrences in inter-aorto-cellar in patients who received only a limited lymphadenectomy diagnosed purely nodal recurrences in inter-aorto-cellar and even in the renal pedicle right after surgery radical $[12,13]$. It seems given the Japanese series more lymphadenectomy is extended to the interaorto-cellar area, most are found infiltrated nodes. On the other hand, over the parietal extension is important (to the serous and beyond), the more of involved lymph nodes and infiltration that goes to the N3 level. Our series is exactly that with a rate of $97 \%$ for pT3 tumors and pT4 with lymph node infiltration N2 and N3. It is for us the first criterion that makes us remember his indication. If all authors are unanimous in saying that patients without lymph node infiltration have an oscillating interesting survival depending on the series ranging from $25 \%$ to $94.4 \%$ [11,13-17], others went up against a state-curative resection before a cancer of the gallbladder with lymph node infiltration tout court [18]. Others report interesting results for a limited interference with the hepatic 
pedicle $[11,19,20]$. Among patients with lymph node infiltration, it is clear that only the hepatic pedicle does not seem very pejorative. In our series, survival at 5 years for a limited interference with the hepatic pedicle is $56 \%$ (data not shown). When infiltrative nodes exist beyond the hepatic pedicle, the survival rate at 5 years fall in a major way. Kondo., et al. [8] reported a zero-survival rate in patients with lymph node infiltration in inter-aorto-cellar in a series of 60patients who underwent extensive lymphadenectomy. For Chiijiwa [19] when a resection with lymphadenectomy is performed and only the hepatic pedicle nodes are invaded (N1), this portends a good prognosis. The same author reported a 5-year survival rate of $28 \%$ in patients with lymph node infiltration N2 [21]. In the series reported by Onoyama [11], 5-year survival rate was $68.7 \%, 60 \%$ and $28.6 \%$ respectively for N0, N1 and N2. Some authors $[22,23]$ are going to associate a pancreatoduodenectomy resection for cleaning as they think that this side of the surgery has its importance in the achievement of optimal surgical faces of cancer of the gallbladder. But could this extensive lymphadenectomy routinely executed justify by a gain in survival at 5 years in the face of risks to the patient? It is reported in recent years either isolated cases or small series of patients with lymph node infiltration in inter-aorto-caval alive beyond 3 years and 5 years. We report (Table 5) patients with long survival and lymph node infiltration in inter-aorto-cellar. The most important experience is that of $\mathrm{Mu}$ rakami [23] reported a series of 113 cancers of the biliary tract (56 bile duct cancers, 6 peripheral cholangio carcinome, 32 ampuloma and 19 cancer of the gallbladder). Of the 17 cases of infiltration in inter-aorto-area, 3 concerned the gallbladder cancer. Overall 5year survival for all etiologies is $24 \%$. For this team, lymphadenectomy is justified only when the nodes are not pathological macroscopically. In the opposed figure (macroscopically infiltrated nodes) the resection is contre-indicated because there the 5-year survival year rate is nil. In our opinion, it is justified to perform an extensive lymphadenectomy for the following reasons:

1. Lymph node infiltration beyond the hepatic pedicle is the one that prevails and does not realize what is left in place in average half the nodes infiltrated into place. There are twothirds of infiltrated nodes of patients in our series (65.4\%).

2. The second relay damage (N2) and that of the third relay (N3) have the same survival at 5 years and therefore requires the completion of lymphadenectomy to levels every 2 simultaneously. In other words, realize the second relay without third is running the risk of letting up infiltrated nodes. Kondo [8] shows that cases classified N0 or N1 + only are free from infiltration N3 (inter-aorto-cellar). Conversely, if the infringement affects the second level (N2 +), $67.7 \%$ of patients at this stage have positive nodes N3 (inter-aorto-caval).
3. Achieving this extensive lymphadenectomy is set to present the most accurate classification for the patient.

4. It is very possible that this extensive lymphadenectomy is itself a therapeutic value by the maximum extirpation of nodes in the patient. In our series, the average number of nodes is 17,5ganglions. In the literature, this ranges from 6 to $22[8,25$, 26,27 ] (Table 4). We must remember that $97 \%$ of our patients with lymph node infiltration beyond the hepatic pedicle had a pT3 tumor or pT4 and that is that when the surgeon is addressing the tumors who are the majority, he must go as far as possible in this lymphadenectomy. Some patients with pT2 and pT3 tumors (tumors confined to the bladder) macroscopically considered as good candidates have infiltrative nodes beyond the hepatic pedicle. They represent $45.6 \%$ of this series and all the problems is to achieve extirpation of nodes to properly classify and have therapeutic value. At present and in our view the 5-year limit of the bar can be a hard limit to achieve in these patients and a 3-year survival may prove as a worthy goal in this series where it is $28.6 \%$. Murakami., et al. [23] and Yonemori., et al. [30] reported prolonged survival in patients with tumors of the bile ducts demonstrating that prolonged survival as well as for cancer of the gallbladder as the rest of the tract cancers bile (Table 5). In fact, it must be very vigilant in the indication of this extensive lymphadenectomy to the extent that we must respect the following:

1. The risk of moderate or minimal morbidity and near zero mortality has to be the goal for the surgeon. We must point that our morbidity and mortality are high. It is our future challenge that we have to reach for decreasing them, ameliorate the postoperative results and then the long terms survival.

2. Insurance to achieve a R0 resection. We have no survival at 3 years for $\mathrm{R} 1$ and $\mathrm{R} 2$ resection.

3. Do not forget that if at present there is no standard treatment for postoperative against the gallbladder cancer. The presence of infiltrated nodes is a situation requiring adjuvant therapy given rate survival. So, this extensive lymphadenectomy allows doing the choice of a future effective adjuvant therapy.

4. Finally, we must not lose sight of the difficulties of achieving lymphadenectomy and especially vis-à-vis the proper hepatic artery and operative length generated by its practice. About $70 \%$ of operating time is devoted to the realization of extensive lymphadenectomy in our experience. 


\begin{tabular}{|l|c|c|c|c|c|c|c|}
\hline Author & Year & Number Of Patient & Global Reach & N0 & N1 & N2 & IAC -CT - SMA \\
\hline Tsukada & 1997 & 111 & $54 \%$ & $46 \%$ & $21,7 \%$ & $31,5 \%$ & $31,5 \%$ \\
\hline Shimada & 1997 & 41 & $63,4 \%$ & $35,6 \%$ & $36,6 \%$ & $51,2 \%$ & $17 \%$ \\
\hline Noie & 1999 & 41 & $34,2 \%$ & $65,8 \%$ & $34,2 \%$ & $19,5 \%$ & $9,8 \%$ \\
\hline Kondo & 2000 & 60 & $73,3 \%$ & $26,7 \%$ & $16,6 \%$ & $56,6 \%$ & $38,3 \%$ \\
\hline Shirai & 2002 & 135 & $44 \%$ & $56 \%$ & $18 \%$ & $26 \%$ & - \\
\hline Ryoko & 2005 & 65 & $41,5 \%$ & 58,5 & - & - & $23,1 \%$ \\
\hline Present series & 2016 & 204 & $56,9 \%$ & $43,1 \%$ & $33,3 \%$ & $16,1 \%$ & $16,7 \%$ \\
\hline
\end{tabular}

Table 4: Infiltrative node and relay in the literature.

IAC: inter aortico-cave.

CT: celiac trunk.

SMA: superior mesenteric artery.

\begin{tabular}{|l|c|c|c|c|c|}
\hline Author & Year & Number of patients & Tumour location & N & Survival \\
\hline Araida & 1993 & 1 & Gallbladder & N3 & 36 months \\
\hline Shirai & 1995 & 3 & Gallbladder & N2 & 4yaers - 6years -3,5years \\
\hline Shinkai & 1996 & 1 & Gallbladder & N3 & 84 months \\
\hline Ijichi & 1996 & 1 & Gallbladder & N3 & 77 months \\
\hline Endo & 1996 & 1 & Gallbladder & N3 & 60months \\
\hline Tsukada & 1997 & 4 & Gallbladder & N3 & Survival beyond 60months \\
\hline Kurokawa & 1999 & 1 & Gallbladder & N3 & 39 months \\
\hline Kondo & 2001 & 1 & Gallbladder & N3 & 69 months \\
\hline Miyasaki & 2004 & 1 & Gallbladder & N3 & 66 months \\
\hline Sasaki & 2004 & 5 & Gallbladder & N3 & $3 / 5$ survival beyond 60months \\
\hline Tokuyama & 2005 & 1 & Gallbladder & N3 & 43 months \\
\hline Sakata & 2007 & 1 & Gallbladder & N3 & 77 months \\
\hline Yonemori & 2011 & 3 & Biliary tree & N3 & 45 months-48months-90months \\
\hline Murakami & 2011 & 17 & Biliary tree & N3 & $24 \%$ 5year survival \\
\hline Liu & 2013 & 6 & Gallbladder & N2 & $16,6 \%$ à 5ans \\
\hline Present series & 2020 & 8 & Gallbladder & N2+N3 & $16,3 \%$ \\
\hline
\end{tabular}

Table 5: Long survival for patient with infiltrative node beyond hepatic pedicle.

\section{Conclusion}

Extensive lymphadenectomy during radical surgery of gallbladder cancer is justified by the 3 and 5-year survival in selected patients. The selection criteria are no major patient organic disease and the possibility of a $\mathrm{R} 0$ resection. Several publications are in line with the realization of extensive lymphadenectomy seen the results achieved in long-term survival and some single lymph node recurrence after radical surgery without lymphadenectomy beyond the hepatic pedicle. The future will show to allow if the extensive lymphadenectomy with the possible importance lymph node extirpation provides help directly to the remote survival but also the choice of adjuvant therapy that considered in practice in coming years.

\section{Bibliography}

1. Ogura Y., et al. "Radical operations for carcinoma of the gallbladder: present status in Japan". World Journal of Surgery 15 (1991): 337-343.

2. JH Donohue., et al. "Carcinoma of the gallbladder. Does radical resection improve outcomes?" The Archives of Surgery 125 (1990): 237-241.

3. Glenn F and DM Hays. "The scope of radical surgery in the treatment of malignant tumors of the extrahepatic biliary tract”. Surgery, Gynecology and Obstetrics 99 (1954): 529-5414.

4. Hueman MT., et al. "Evolving treatment startegies for gallbladder cancer". Annals of Surgical Oncology 16 (2009): 2101212115. 
5. Shimada H., et al. "The role of lymph node dissection in the treatment of gallbladder carcinoma". Cancer 79 (1997): 892899.

6. K Tsukada., et al. "Lymph node spread from carcinoma of the gallbladder". Cancer 80 (1997): 661-667.

7. Shirai Y., et al. "Identification of regional lymphatic system of the gallbladder by vital staining". British Journal of Surgery 79 (1992): 659-662.

8. Kondo S., et al. "Regional and para-aortic lymphadenectomy in radical surgery for advanced gallbladder carcinoma”. British Journal of Surgery 87 (2000): 418-422.

9. International Union contra la cancrum. Galbladder (ICD0156.0). In: Hermanek P, Sobin LH, eds. TNM classification of malignant tumors. 4th ed. Berlin: Springer-Velag, (1987): 56-58.

10. American Joint Committee on Cancer. Gallbladder. In: Beahrs OH, Henson DE, Hutter RVP, MH Myers, eds. Manual for staging of cancer. 3rd ed. Philadelphia: JB Lipincott (1988): 93-98.

11. Yamaguchi K., et al. "Retrospective analysis of 70 operations for gallbladder carcinoma". British Journal of Surgery 84 (1997): 200-204.

12. Shirai Y., et al. "Lymph node recurrence of gallbladder carcinoma successfully managed by systemic chemotherapy with 5-fluorouracil and mitomycin C: report of a 7-year survivor". European Journal of Surgical Oncology 23 (1997): 457-458.

13. Noia T Kubota K., et al. "Proposal on the extent of lymph node dissection for gallbladder carcinoma”. Hepato-Gastroenterology 46 (1999): 2122-2127.

14. Shirai Y., et al. "Radical surgery for gallbladder carcinoma. Long-term survival”. Annals of Surgery 215 (1992): 565-568.

15. Onoyama H., et al. "Extended cholecytectomy for carcinoma of the gallbladder". World Journal of Surgery 19 (1995): 758-763.

16. Rückert JC., et al. "Surgery for carcinoma of the gallbladder". Hepato-Gastroenterology 43 (1996): 527-533.

17. DL Bartlett., et al. "Long term results after-resection for gallbladder cancer. Implications for staging and management". Annals of Surgery 224 (1996): 639-646.

18. Benoit $\mathrm{S}$ and Panis YPL. "Faniez University and the French Association for Surgical Research. Long-term results after-curative resection for carcinoma of the gallbladder". The American Journal of Surgery 175 (1998): 118-122.

19. Chiijiwa K., et al. "Clinicopathologic differences entre longterm and short-term postoperative survivors with advanced carcinoma". World Journal of Surgery 21 (1997): 98-102.

20. Chijiiwa K., et al. "Surgical treatment of patients with T2 gallbladder carcinoma invading the subserosal layer". Journal of the American College of Surgeons 192 (2001): 600-607.
21. Noshiro H., et al. "Role of surgery for gallbladder carcinoma with special reference to lymph node metastasis and placement using Western and Japanese classification systems". World Journal of Surgery 24 (2000): 1271-1277.

22. Shinkai H., et al. "A case of gallbladder cancer with para-aortic lymph node metastasis Who has survived more than seven Years After the primary extended radical operation Hepato". Gastroenterology 43 (1996): 1370-1376.

23. Y Murakami., et al. "Is paraortic lymph node metastatsis has against-indication for radical resection in biliairy carcinoma?" World Journal of Surgery 35 (2011): 1085-1093.

24. R Sasaki., et al. "Long term results of central inferior (S4 + S5) and hepatic subsegmentectomy pancreatoduodenectomy combined with extended lymphadenectomy for gallbladder carcinoma with invasion subserous or mild (pT2-3) and nodal involvement: a preliminary report". Hepatogastroenterology 51 (2004): 215-218.

25. J Shirai Y., et al. "Number of positive lymph nodes indépendamment determined the prognosis after-resection in patients with gallbladder carcinoma". Annals of Surgical Oncology 17 (2010): 1831-1840

26. Liu GJ., et al. "Radical lymph node dissection and assessment: impact on gallbladder cancer prongnosis". World Journal of Gastroenterology 19 (2013): 5150-5158.

27. Shirai Y., et al. "Regional lymphadenectomy for gallbladder cancer: rational extent, technical details and outcome patients". World Journal of Gastroenterology 18 (2012): 2775-2783.

28. Nagakura S., et al. "Clinical significance of lymph node micrometastasis in galmbladder carcinoma”. Surgery 129 (2001): 704-713.

29. Tanabe M., et al. "Is lymph node micrometastasis in gallbladder cancer has significant prognostic factor?" Hepatogastroenterology 59 (2012): 31-35.

30. Yonemori A., et al. "Hirano Para-aortic node micrometastasis lymp in patients with node negative biliary cancer". Digestive Surgery 28 (2011): 315-321.

\section{Assets from publication with us}

- Prompt Acknowledgement after receiving the article

- Thorough Double blinded peer review

- Rapid Publication

- Issue of Publication Certificate

- High visibility of your Published work

Website: https://www.actascientific.com/

Submit Article: https://www.actascientific.com/submission.php Email us: editor@actascientific.com

Contact us: +919182824667 